\title{
The Influence of Transverse CSR Structure on Headquarters/Subsidiary Integration
}

\section{Luciano Barin Cruz *}

E-mail address: luciano.barin-cruz@hec.ca HEC Montréal

Montréal, Canada.

\section{Eugenio Avila Pedrozo}

E-mail address: eapedrozo@ea.ufrgs.br Universidade Federal do Rio Grande do Sul Porto Alegre, RS, Brazil.

\section{Vania de Fátima Barros Estivalete}

E-mail address: vaniafbe@terra.com.br Universidade Federal de Santa Maria Santa Maria, RS, Brazil.

\section{Debora Nayar Hoff}

E-mail: deborahoff@unipampa.edu.br Universidade Federal do Pampa, Campus Sant'Ana do Livramento Sant'Ana do Livramento, RS, Brazil

\section{ABSTRACT}

Some studies have already highlighted the effects of the introduction of Corporate Social Responsibility [CSR] projects into Multinational Corporations' $[\mathrm{MNC}]$ strategies. However, little attention has been paid to the influence of transverse CSR structure on headquarters/subsidiary integration. In this article, we begin with the following question: What is the influence of the introduction of a centralized/decentralized structure on conducting a CSR strategy in a MNC? Our main objective is to identify conditions through which the structure of the CSR department influences the CSR strategy of the MNC. We define transverse CSR structure as: (1) the existence of a CSR directory at the headquarters level and a CSR representative at the subsidiary level, and (2) the existence of representatives from different areas who participate in meetings or committees to make decisions about CSR strategy. We argue that a transverse CSR structure favors consideration of global and local CSR demands by headquarters and subsidiaries. This process takes place through the mediation of three main elements: information exchange, awareness activities and definition of objectives.

Key words: corporate social responsibility; transverse CSR structure; multinational corporations.

Received 08.12.2008; received in revised form 08.12.2009.

Copyright (C) 2010 Brazilian Administration Review. All rights reserved, including rights for translation. Parts of this work may be quoted without prior knowledge on the condition that the source is identified.

* Corresponding author: Luciano Barin Cruz

Édifice Côte-Sainte Catherine, 3000, chemin de la Côte-Sainte-Catherine, Montréal (Québec) - Canada. Zip Code: H3T 2A7 


\section{INTRODUCTION}

Multinational Corporations [MNCs] develop coordination and control activities (Allaire, 1984; Baliga \& Jaeger, 1984; Edstrom \& Galbraith, 1977; Elis, 2000; Harzing, 2001; Jaeger, 1983; Kim \& Mauborgne, 1991, 1993; Kranias, 2001; Martinez \& Jarilo, 1989; Molm, Takahashi, \& Peterson, 2003; Nohria \& Ghoshal, 1994; Ouchi \& Jaeger, 1978; Perlmuter, 1984; Taggart, 1997) in order to improve the integration of their headquarters with different subsidiaries. Considering local characteristics, this is not an easy task. Language, values and traditions are important aspects to consider.

The emergence of the sustainable development debate has introduced an additional concern about headquarters/subsidiary integration: the Corporate Social Responsibility [CSR] discussion. MNCs are required to have explicit CSR strategies not only at the headquarters level, but also at the subsidiary level; thus, the way that MNCs structure their CSR departments is an important element of the headquarters/subsidiary integration process.

In this article, we begin with the following question: What is the influence of the introduction of a centralized/decentralized structure on conducting a CSR strategy in a MNC? Our main objective was to identify the conditions through which the structure of the CSR department influences the CSR strategy of the MNC. As our main contribution, we argue that a transverse CSR structure favors consideration of global and local CSR demands by headquarters and subsidiaries. This process takes place through the mediation of three main elements: information exchange, awareness activities and definition of objectives. We define transverse CSR structure as: (a) the existence of a CSR directory at the Headquarters level and a CSR representative at the Subsidiary level, and (b) the existence of representatives from different areas who participate in meetings or committees to make decisions about CSR strategy.

The remainder of this article is structured as follows. In the first section, we discuss theoretical concepts related to headquarters/subsidiary integration and CSR strategies. In the second section, we present the method, and in the third section we present an analysis of two MNCs' case studies, highlighting the propositions and the framework. Finally, in the last section, we present the discussion and conclusions.

\section{MNCS - HEADQUARTERS/SUBSIDIARY INTEGRATION}

Integration between headquarters and subsidiaries is one of the central topics in the MNC literature (expatriation and employee transfer - Edstrom \& Galbraith, 1977; Harzing, 2001; formal and informal transference of information - Kranias, 2001; Martinez \& Jarilo, 1989; organizational culture - Allaire, 1984; Baliga \& Jaeger, 1984; Jaeger, 1983; Kranias, 2001; Nohria \& Ghoshal, 1994; Ouchi \& Jaeger, 1978, procedural justice - Elis, 2000; Kim \& Mauborgne, 1991, 1993; Molm et al., 2003; Taggart, 1997, and definition of objectives - Elis, 2000; Perlmuter, 1984). Different factors that lead to better integrated relations have been proposed and analyzed, with various implications for the MNCs' strategies.

Considering these factors, Jaeger (1983) highlights some characteristics of the culture control structure. He states that interpersonal interactions are very important in this kind of structure. All of the members of the culture share expectations and performance, and commitments emerge from interpersonal relationships. Feedback is passed from individual to individual and can be very subtle. The culture becomes a rich behavioral guide. In organizations where control is directed by cultural structure, interpersonal relations are more informal (Jaeger, 1983; Kranias, 2000).

Procedural justice is also an important factor in the headquarters/subsidiary integration literature. Kim and Mauborgne (1993) define procedural justice as the extent to which the dynamics of a multinational corporation's strategy-making process are judged to be fair by the top managers of its subsidiaries. They 
propose five characteristics of procedural justice perceived by a subsidiary's managers: (a) head office management is knowledgeable about the local situation of subsidiary units, (b) two-way communication exists in the MNC's strategy-making process, (c) the head office is fairly consistent in making decisions across subsidiary units, (d) subsidiary units can legitimately challenge the strategic views of the head office, and (e) subsidiary units receive an account of the MNC's final strategic decisions.

The definition of objectives is highlighted by Elis (2000). He states that MNC managers should establish a decision process for strategic objectives. This process should stimulate bilateral communication, information exchange, reliability of information, autonomy and knowledge of local context. Such a decision process could improve the perception of procedural justice.

Expatriation is another important factor. Edstrom and Galbraith (1977) state that the expatriation process can create an international, interpersonal and verbal information network through the MNC. The main reasons provided by Edstrom and Galbraith (1977) include filling important positions in subsidiaries, the development of international managers and the maintenance of structure and decision making.

Martinez and Jarilo (1989) summarize these important factors when listing some formal and informal coordination mechanisms used by MNCs. The formal mechanisms are: departmentalization or grouping of organizational units, shaping the formal structure; centralization or decentralization of decision-making through the hierarchy or formal authority; formalization and standardization (written policies, rules, job descriptions and standard procedures) through instruments such as manuals, charts, etc.; planning (strategic planning, budgeting, functional plans, scheduling, etc.); and output and behavior control (financial performance, technical reports, sales and marketing data, etc.), as well as direct supervision.

The informal mechanisms are: lateral or cross-departmental relations (direct managerial contact, temporary or permanent teams, task forces, committees, integrators and integrative departments); informal communication (personal contacts among managers, management trips, meetings, conferences, transfer of managers, etc.); and socialization (building an organizational culture of known and shared strategic objectives and values by training, transfer of managers, career path management, measurement and reward systems, etc).

Although some authors (Dam \& Scholtens, 2008; Levis, 2006) discuss CSR aspects in MNCs, the influence of the structure of a specific CSR department on the MNC CSR strategy and, as a consequence, on headquarters/subsidiary integration, has rarely been addressed. The adoption of a centralized/decentralized structure for the CSR department is one point that requires further investigation.

\section{CSR StRATEGies}

The debate on sustainable development issues has become increasingly important in recent years. Since sustainable development was defined by the Brundtland Report as "development that meets the needs of the present without compromising the ability of future generations to meet their own needs" (World Commission on Environment and Development, 1987, p. 43), it has gained attention in the agendas of public and private managers.

From this general concept emerged the debate on Corporate Social Responsibility [CSR], which reflects the incorporation of sustainable development into companies' strategies. As defined by the European Commission (2002, p. 5) and recalled by Steurer, Langer, Konrad and Martinuzzi (2005), CSR is "a concept whereby companies integrate social and environmental concerns in their business operations and in their interaction with their stakeholders on a voluntary basis".

Many authors (Aguilera, Rupp, Williams, \& Ganapathi, 2007; Bansal, 2005; Barin-Cruz, Pedrozo, Bacima, \& Queiroz, 2007; Barnett, 2007; Basu \& Palazzo, 2008; Mackey, Mackey, \& Barney, 2007; Matten \& Moon, 2008, among others) have developed arguments and propositions concerning the CSR issue. 
Considering the way CSR is structured within firms, Husted (2003) lists three types of CSR governance: (1) outsourcing CSR through corporate charitable contributions, (2) internalizing CSR through in-house projects or (3) using a collaborative model. These types are directly related to the companies' relationships with their stakeholders and to the decision on whether to centralize or decentralize CSR projects within the MNC.

The different kinds of CSR governance can influence ecoinitiatives from the employees (Ramus \& Steger, 2000) and the consequent improvement in companies' environmental performance. In this sense, Bansal and Roth (2000) and Bansal (2003) insist on individual action. The former affirms that one of the important aspects to consider with regard to corporate ecological responsibility is the salience and interest of ecological questions for the individuals who compose the company. In other words, to what extent does an ecological question make sense to these individuals, and to what extent will they act regarding to their possible ecological values? The latter affirms that individual interests can be stimulated through education, training and information availability, which allow the individuals to make connections between poverty and environmentally and socially unsustainable practices. The way CSR is structured in the MNC may have an impact on the behavior of individuals inside the firm.

There are other potential impacts of CSR structure. Sometimes, it makes companies change values and create new needs (Fergus \& Rowney, 2005). Furthermore, it can encourage environmental matters to be viewed as opportunities rather than threats (Sharma, 2000). These different types of CSR governance can also influence the behavior and, consequently, evolution of a company's CSR strategy, as stated by Raiborn and Payne (1990) and Payne and Raiborn (2001), from the basic level (reactive approach to environmental and social laws) to a more practical level, and finally ending at a theoretical level (proactive approach to environmental and social laws).

Thus, the conclusions about the impact of CSR structure are still varied and indicate different potential avenues of research. Therefore, the CSR structure and its influence on MNCs' CSR strategy and, as a consequence, on headquarters/subsidiary integration still require further research.

\section{METHOD}

The research design is based on Eisenhardt's (1989) proposition. We have followed the eight steps suggested by the author, as shown in Table 1 . We highlight that we do not intend to build a new theory, but to make a contribution from the cases under study. We note, as suggested by Siggelkow (2007), that we use our case studies as an inspiration for theory on CSR. In other words, through exploratory case studies, we propose an initial contribution to the literature on CSR (specifically, considering CSR structure and its influence on MNCs' CSR strategies).

Table 1:

\section{Research Design}

\begin{tabular}{lll}
\hline Steps (Eisenhardt, 1989) & Activity & Applicability on this research \\
\hline 1. Getting started & Definition of research question & $\begin{array}{l}\text { - What is the influence of the introduction } \\
\text { of a centralized/decentralized structure on } \\
\text { conducting a CSR strategy in a MNC? }\end{array}$ \\
& Specified population & $\begin{array}{l}\text { - Biggest retailer MNCs in France. } \\
\text { 2. Selecting Cases }\end{array}$ \\
& $\begin{array}{l}\text { - Brazilian subsidiary as one of the } \\
\text { strongest branches }\end{array}$ \\
\hline
\end{tabular}

Continue 
Table 1 (continued)

\begin{tabular}{|c|c|c|}
\hline Steps (Eisenhardt, 1989) & Activity & Applicability on this research \\
\hline $\begin{array}{l}\text { 3. Crafting Instruments } \\
\text { and Protocols }\end{array}$ & Multiple data collection methods & $\begin{array}{l}\text { - Combination of in-depth interviews and } \\
\text { document analysis }\end{array}$ \\
\hline \multirow[t]{2}{*}{ 4. Entering the Field } & $\begin{array}{l}\text { Flexible and opportunistic data } \\
\text { collection methods }\end{array}$ & $\begin{array}{l}\text { - Introduction of new questions during } \\
\text { interviews }\end{array}$ \\
\hline & & - Incorporation of new interviewees \\
\hline \multirow[t]{2}{*}{ 5. Analyzing Data } & - Within-case analysis & - Deep analysis of each individual case \\
\hline & - Cross-case pattern search & $\begin{array}{l}\text { - Search patterns from the case's cross- } \\
\text { analysis }\end{array}$ \\
\hline \multirow[t]{2}{*}{ 6. Shaping Propositions } & $\begin{array}{l}\text { - Iterative tabulation of evidence } \\
\text { for each construct }\end{array}$ & $\begin{array}{l}\text { - Iterative presentation of data for both } \\
\text { cases }\end{array}$ \\
\hline & $\begin{array}{l}\text { - Search for the "why" behind } \\
\text { relationships }\end{array}$ & -Identification of propositions \\
\hline 7. Enfolding Literature & Comparison with similar literature & $\begin{array}{l}\text { Definition of propositions using similar } \\
\text { theory to justify developed concepts }\end{array}$ \\
\hline 8. Reaching Closure & $\begin{array}{l}\text { When to stop iterating theory and } \\
\text { data }\end{array}$ & $\begin{array}{l}\text { Definition of a framework from the } \\
\text { propositions as the output of the research }\end{array}$ \\
\hline
\end{tabular}

\section{Data Collection}

The data collection process is defined by the first four steps: (1) getting started, (2) selecting cases, (3) crafting instruments and protocols, and (4) entering the field.

\section{Getting Started and Selecting Cases}

We focus here on identifying conditions through which the structure of the department of CSR influences the CSR strategy of the MNC.

We have carried out two case studies. Both cases represent important MNCs in the worldwide retail sector. Both of them consider their respective Brazilian Subsidiaries as one of the major branches for their international activities.

MNC A has a strong international presence (11 countries) with more than 146,000 employees and 24.97 billion euros in sales and activity in the retail sector in several areas, including hypermarkets, supermarkets, discount stores, small stores, restaurants and cafeterias and other activities. In Brazil, MNC A has been a partial owner of its Brazilian subsidiary since 1999. Today, the MNC owns 50\% of the stock of the Brazilian subsidiary. However, the Brazilian subsidiary already had a history before MNC A became involved, including an important history in the Brazilian market and historical social activity in the communities in which it operates. In 2007, the Brazilian subsidiary had 575 stores located in many Brazilian states and had around 6.5 billion euros in sales and 13.8\% of the market share, making it one of the two biggest retail MNCs in Brazil.

MNC B was, in 2007, the largest MNC in the retail sector in Europe and the second largest in the world. It operates in 30 countries, with around 490,000 employees and 102.3 billion euros in sales in different segments of the retail industry, such as hypermarkets, supermarkets, discount stores and convenience stores. In Brazil, in 2007, the subsidiary had around 512 stores. The MNC closed the year with around 7.2 billion euros in sales. 


\section{Crafting Instruments and Protocols}

Two data collection methods were used for both MNCs: (1) interviews with managers involved in making CSR strategy, and (2) the collection of internal and external documents.

Document-based research and interviews were conducted between August and December, 2006. Seventy-nine documents were analyzed for MNC A, and 66 documents were analyzed for MNC B (in both cases, we highlight the CSR reports from between 2002 and 2005, published internationally by the MNCs). At MNC A, 13 interviews were conducted with managers in charge of CSR practices at the Headquarters and Brazilian Subsidiary levels. The interviews were conducted in French and Portuguese and followed a semi-structured protocol, with each interview lasting about 50 minutes. A profile of the interviewees can be seen in Table 2 .

Table 2:

\section{Profile of the Interviewees at MNC A}

\begin{tabular}{ll}
\hline $\mathrm{s}$ & Level \\
\hline A1. Sustainable Development Director & Headquarters \\
A2. Responsible for sustainable development & Headquarters \\
A3. RH International Director & Headquarters \\
A4. Quality Director & Headquarters \\
A5. Manager of Bio and Nutrition Products & Headquarters \\
A6. Manager of Partnerships with the Community & Headquarters \\
A7. Production Director & Headquarters \\
A8. Manager of Ethics in the MNC & Headquarters \\
A9. Institute Director of the Brazilian Subsidiary & Subsidiary \\
A10. Responsible for HR in Brazil & Subsidiary \\
A11. Responsible for the Caras do Brasil (Faces of Brazil) Program & Subsidiary \\
A12. Manager of the Caras do Brasil (Faces of Brazil) Program & Subsidiary \\
A13. Responsible for Waste Management in Brazil & Subsidiary \\
\hline
\end{tabular}

At MNC B, 10 interviews were conducted with some of the main individuals responsible for sustainable development at the Headquarters and Brazilian Subsidiary levels. As with MNC A, the interviews were conducted in French and Portuguese and followed a semi-structured questionnaire, with each interview lasting around 35 minutes. The profile of the interviewees from MNC B can be seen in Table 3.

Table 3:

\section{Profile of the Interviewees at MNC B}

\begin{tabular}{lr}
\hline \multicolumn{1}{c}{ Interviewees } & \multicolumn{1}{c}{ Level } \\
\hline B1. Sustainable Development Manager of the Hypermarkets & Headquarters \\
B2. Sustainable Development Manager of the Supermarkets & Headquarters \\
B3. Manager of Products Related to Sustainable Development & Headquarters \\
B4. Sustainable Development Ambassador of a Hypermarket & Headquarters \\
B5. Sustainable Development Ambassador of a Hypermarket & Headquarters \\
& Continue
\end{tabular}




\section{Table 3 (continued)}

\begin{tabular}{lc}
\hline \multicolumn{1}{c}{ Interviewees } & Level \\
\hline B6. Responsible for the Waste Management of a Hypermarket & Headquarters \\
B7. Responsible for a Waste Recycling Company that Works for MNC B & Headquarters \\
B8. Responsible for Communication at MNC B Linked to the Sustainable Development Area & Headquarters \\
B9. Responsible for Sustainable Development in the Brazilian Subsidiary & Subsidiary \\
B10. Responsible for the Relationship Program with Suppliers in Brazil & Subsidiary \\
\hline
\end{tabular}

Note. Source: prepared by the authors.

\section{Entering the Field}

In both cases, we developed an initial semi-structured questionnaire with questions such as:

Please talk about the institutional policies for CSR at your MNC and at the Brazilian subsidiary.

How can CSR be considered in the strategy of a MNC? And at the Brazilian subsidiary?

How is CSR structured in the MNC? Is there a specific department? How is this department composed? How do you deal with centralized and decentralized aspects? And at the Brazilian subsidiary?

How does the MNC share its results with stakeholders? And the Brazilian subsidiary?

Are there specific objectives for CSR? How are they defined? And at the Brazilian subsidiary?

Are the top managers engaged with CSR decisions within the MNC? And in the Brazilian subsidiary?

How do you inform the different stakeholders about CSR? And at the Brazilian subsidiary?

How would you describe the relationship with the Brazilian subsidiary?

We adopted this flexible process to allow for the emergence of specific and important new elements from the empirical field. Moreover, we developed this process in conjunction with the chosen interviewees. In both MNCs, we started by interviewing the main CSR managers of each MNC; in the first interview, we asked them to recommend new interviewees that could support our study. Each new interviewee was a potential source of material for the next interview. We followed this process at the Headquarters as well as at the Subsidiaries.

\section{Data Analysis}

The data analysis process includes the final four steps: (5) analyzing data, (6) shaping propositions, (7) enfolding literature and (8) reaching closure.

\section{Analyzing Data}

In both MNCs, data analysis followed two methods: (1) within-case analysis, and (2) cross-case pattern search.

The within-case analysis was conducted through separate analysis of each case. We generated 100 pages of interview transcripts and 79 analyzed documents for MNC A. For MNC B, we generated 70 pages of interview transcription and 66 analyzed documents. Data were analyzed independently for 
each case. From these analyses, the specific influences of CSR structures on each case emerged, which helped us to identify the MNCs' idiosyncrasies.

The cross-case pattern search was conducted after the within-case analysis. We identified some general elements to describe the specific CSR structure of each MNC. In other words, we identified general concepts to manage these idiosyncrasies. We developed this process by contrasting our data with the established CSR and MNC literature (as we explain in the literature section below).

\section{Shaping Propositions and Enfolding Literature}

We have conducted an iterative presentation of each conceptual element. We present our resulting analysis through some quotations (translated from Portuguese and French to English) from interviewees from both MNCs to justify the emergence of each element. From this iterative presentation, we define some propositions for each element, linking the existent CSR and MNC literature to our data. Then, we include previous literature by contrasting our data (CSR structure of each MNC) with similar literature on CSR and MNCs. It is important to highlight that the elements and the propositions are the result of the crossing process among interviews, documents and literature.

\section{Reaching Closure}

The result of these steps is our proposed framework, which reflects the propositions suggested during the analysis and our iterative efforts to link the elements that emerged from the data with the existent literature. The framework provides some initial material with which to fill the gap in the CSR and MNC literature suggested by our research question.

\section{RESULTS OF ANALYSIS}

We focus our analysis on the presentation of three main elements that emerged from the case studies: information exchange, awareness activities and definition of objectives. Information exchange is defined here as the information on sustainability issues exchanged through formal and informal activities. An awareness activity is defined as the employees' awareness of sustainability issues stimulated by formal and informal activities. Definition of objectives concerns sustainability issues stimulated by formal and informal activities.

These elements are decisive mediators of the influence of CSR structure on headquarters/subsidiary integration. As highlighted by interviewees A1, B1 and B8, both MNCs have a transverse structure for their CSR strategy:

"We have not created a strong central structure, but we have created a sustainable development committee. This sustainable development committee has 40 experts in France and 10 international experts. These experts are people with experience in specific areas and they have double functions" (Interviewee A1)

"The sustainable development is always transverse [...] therefore, we have people in a specific CSR structure but also people that work with CSR and are located in other classical areas of the Company" (Interviewee B1)

"At the corporate level there is the sustainable development directory $[\ldots]$ in each country, we have some sustainable development representatives [...] we establish dialogue with them [...] they exchange information with us, but they can also feel that they have some support at the corporate level” (Interviewee B8)

Figure 1 presents the framework and related propositions. 


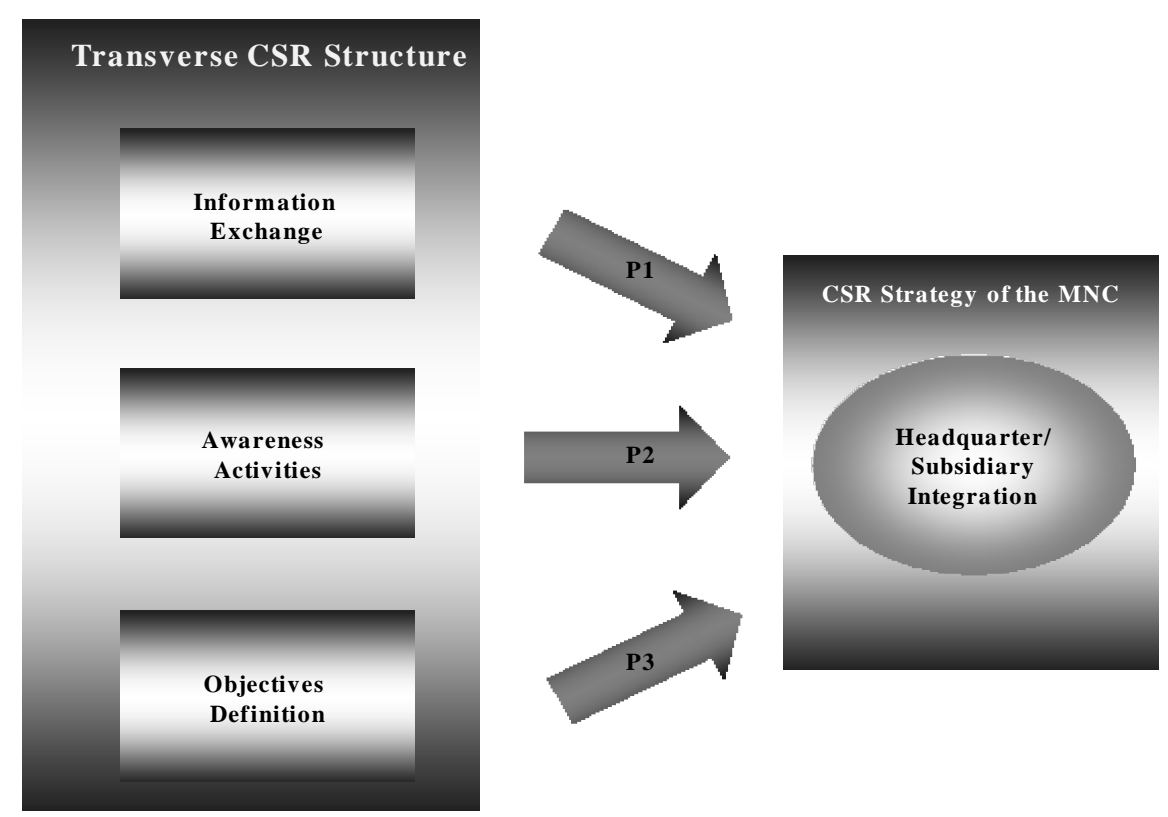

P1: Through information exchange, Transverse CSR Structure favor CSR Strategy and, as consequence, improve integration between Headquarters and Subsidiaries.

P2: Through awareness activities, Transverse CSR structure favor CSR Strategy and, as consequence, improve integration between Headquarters and Subsidiaries.

P3: Through objectives definition, Transverse CSR structure favor CSR Strategy and, as consequence, improve integration between Headquarters and Subsidiaries.

Figure 1: Framework - Influence of Transverse CSR Structure on headquarters/subsidiary Integration

\section{Information Exchange}

Both MNC A and MNC B have developed a transverse structure that has stimulated the exchange of information. At MNC A, we see that it was created through the use of some formal activities (as stated by Martinez \& Jarilo, 1989), such as international internal conferences, internal newsletters and CSR reports. Interviewees A4 and A12 highlighted the conferences carried out with managers from different areas and their consequent impact on information exchange.

"It is the only situation in which people from information technology, logistics, marketing, and quality sit together at the same table at the same meeting [...] they discuss their experiences and talk about sustainable development problems” (Interviewee A4)

“The most important (advantage) is the information exchange for problem solving [...] oftentimes, we don't have a solution, but they have already found how to work with the same problem [...] (Interviewee A12)

A transverse CSR structure with a committee formed by managers from different areas at the corporate level and representatives from each subsidiary stimulates information exchange about different CSR problems and solutions from each specific area or country.

At MNC B, there is also an international structure for CSR, which is supported by representatives from other areas with a dual function. Moreover, the subsidiaries (including the one studied in Brazil) have a transverse structure that stimulates information exchange through formal activities (as stated by Martinez \& Jarilo, 1989). Interviewee B8 remembered different tools used for communication; in particular, internet use allows for international exchange.

"We work with a collaborative platform on the Internet by uploading documents [...] therefore, it serves as a library, a place for information exchange [...] everything we say in videoconferences is put on this platform

$[\ldots]$ every document that each country wants shared can be put there $[\ldots]$ there is also the sustainable 
development report that is also a communication mechanism [...] It is sent to every country [...] it is translated into English and Spanish [...] therefore, it is also a way to see how people work on this subject in other countries" (Interviewee B8)

Furthermore, at MNC B, the transverse structure of CSR at the headquarters level (considering the participation of different areas) as well as in subsidiaries (considering the CSR representatives in each country) leads to an improvement in the exchange of information.

The information exchange allows headquarters (France) and the subsidiary (Brazil) to understand the practices carried out in different countries' contexts. The transverse CSR department does not impose rules, but creates an appropriate environment for discussion and exchanging of ideas. The Brazilian reality, with its specific social problems, is respected, and projects involving the participation of communities and child care receive special attention from both MNCs. This is also the case in France. Environmental concerns related to waste procedures deserve an important place in the CSR strategy of these MNCs in these countries. The information exchanges result in both sides being better informed but do not impose the same practices on them.

Thus, Proposition 1 may be stated as follows:

P1: Through information exchanges, a transverse CSR structure favors CSR strategy and, as a consequence, improves integration between Headquarters and Subsidiaries.

\section{Awareness Activities}

Transverse CSR structure can also enable better awareness concerning sustainable development. It can have an impact throughout the different areas involved within the MNC, and even outside via the main stakeholders.

At MNC A, the transverse CSR structure allows for each area to have a representative on the international CSR committee. In this structure, each representative has the task of disseminating most of the information about the CSR strategy and making the employees of his/her area aware of CSR concerns. The same happens in the case of the subsidiaries; as the representative of each subsidiary participates in the international committee, they are responsible for making the corporate level aware of CSR demands at the local level and also for making the local level aware of CSR orientations. The CSR director also develops some awareness through activities with the main stakeholders. Interviewee A1 highlighted some of these characteristics:

"Therefore, everyone is an expert in his or her specific area [...] they are responsible for answering questions in their areas [...] and I, as the sustainable development director, I facilitate this sustainable development committee" (Interviewee A1)

“I facilitate this committee, and I answer questions, I go to schools, I answer the notation agencies' surveys, I meet socially responsible shareholders” (Interviewee A1)

At MNC B, there is not a transverse committee as there is at MNC A. However, it also has representatives from some areas responsible for communicating with the CSR area and giving information sessions concerning sustainable development. In each country, the CSR representative has the role of developing internal employees' awareness of activities at the local level as well as external stakeholders' awareness. Interviewee B8 highlighted some of these practices:

"There are several things [...] all our policy is based on our values [...] MNC A undertook, in recent years, many awareness activities on their values [...] in many countries, we created awareness campaigns [...] there can be specific training in some stores [...] I will speak for the stores [...] they have environmental world day [...] during this day, every store of the MNC is mobilized [...] there are different actions in different countries $[\ldots]$ in each new store, we give a training course during which we talk about the subject” [...] (Interviewee B8)

In both MNCs, we see the possible informal impacts of these transverse CSR structures on internal and external awareness. As stated by Martinez and Jarilo (1989), lateral or cross-departmental 
relations, informal communication and socialization are created with the awareness activities and can stimulate headquarters/subsidiary integration.

Although information exchange and awareness are complementary activities, awareness is an important tool for working with local stakeholders. The Brazilian cultural and institutional contexts are marked by the participation of many NGOs and local communities acting for the improvement of society's quality of life. This also happens in France. Manifestations of social and human rights are a characteristic of this country. The transverse CSR structure permits local awareness activities to be carried out with local stakeholders, improving the relationship between company and society.

Therefore, we may state Proposition 2 as follows:

P2: Through awareness activities, transverse CSR structure favors CSR strategy and, as a consequence improves integration between Headquarters and Subsidiaries.

\section{Definition of Objectives - Dialogue with Stakeholders}

A transverse CSR structure can also allow for an improved definition of objectives. At MNC A, the definition of objectives involves CSR practices and is defined by the local realities of each Subsidiary. The transverse CSR structure allows for each subsidiary to attend to its social and environmental demands and to adapt the corporate objectives to this local reality. The transverse CSR structure obliges the MNC to adapt its indicators to the social and environmental characteristics of each country. The project "Caras do Brasil" is a point in question, in which MNC A develops a local project based on its local objective of improving economic conditions in local communities. Interviewees A1 and A2 highlighted these characteristics:

"It is difficult for everyone in the MNC to think the same way [...] an important point for us is that each Subsidiary has autonomy [...] we keep the brand and some projects of the local structure” [...] (Interviewee A1)

"We see that in each country, the indicators have different meanings $[\ldots]$ some indicators are better for some specific countries than others [...] therefore, today, we enter a phase in which we ask each country about the most adapted indicators, those that really matter [...] so, we think that our next reports will have different indicators $[\ldots]$ therefore, it is important to understand each country and to have interesting indicators for each country" (Interviewee A1)

"I think that sustainable development should be adapted to each country because every country is different" (Interviewee A2)

At MNC B, the transverse CSR structure also allows for the CSR objectives to be defined with respect to the local social and environmental demands of each subsidiary. Each subsidiary considers the macro orientations held at the corporate level. However, it also has the responsibility of identifying local characteristics and defining how it can develop programs that are simultaneously related to the corporate orientations and assist this local reality. Interviewees B9 and B8 highlighted these characteristics:

"I always have to implement this concept [...] think globally and act locally [...] my approach has to be different” (Interviewee B9)

"Each Subsidiary adapted the global sustainable development policy of the MNC [...] this is the reason why some countries concentrate on social projects, as in Latin America [...] in other countries, like in Europe, they also do a lot of social projects, but they concentrate on environmental projects [...]” (Interviewee B8)

"The idea is to have local teams thinking about sustainable development issues [...] this means the MNC is engaged in many areas, so each country, according to its specific characteristics, adapted some projects" (Interviewee B8)

At this time, both formal and informal integration mechanisms (Martinez \& Jarilo, 1989) are developed through the transverse CSR structure in MNCs. Lateral or cross-departmental relations, 
informal communication and socialization are stimulated and allow for the improvement of the process of defining objectives. Strategic planning, as a formal mechanism, is also improved through the transverse structure. Local demands are considered, and local social and environmental characteristics become part of corporate strategic planning. Again, the cultural and institutional characteristics of each country can be considered when making the adjustment between global and local CSR objectives.

Therefore, we may state Proposition 3 as follows:

P3: Through definition of objectives, a transverse CSR structure favors CSR strategy and, as a result, improves integration between Headquarters and Subsidiaries.

\section{Discussion AND CONCLUSIONS}

In this study, we have argued that a transverse CSR structure favors consideration of global and local CSR demands by headquarters and subsidiaries. We have defined transverse CSR structure as: (1) the existence of a CSR directory at the Headquarters level and a CSR representative at the subsidiary level and (2) the existence of representatives from different areas who participate in meetings or sit on committees to make decisions concerning CSR strategy.

Following the steps suggested by Eisenhardt (1989) and the suggestion to use case studies in a more persuasive way (Siggelkow, 2007), we use our case studies as inspiration to contribute to theory on CSR. Thus, this research contributes by suggesting that through mechanisms such as information exchange, awareness activities and definition of objectives, a transverse CSR structure favors CSR strategy in the MNC (consideration of global and local CSR demands) and, in consequence, helps with headquarters/subsidiary integration. Therefore, the transverse CSR structure allows for a sort of mix between a centralized and decentralized structure in the MNC.

\section{Managerial Implications}

The results of this research suggest that managers should stimulate the creation of transverse CSR structures if they wish to improve headquarters/subsidiary integration regarding the MNC's CSR strategy. We highlight that this transverse CSR structure must respect the local cultural and institutional characteristics of the countries involved.

This can be achieved by appointing CSR representatives for each subsidiary, as well as representatives from some specific areas (marketing, human resources, production, logistics, etc.) participating in CSR committees and decisions. Through information exchange, awareness activities and definition of objectives, formal and informal mechanisms can be stimulated to improve headquarters/subsidiary integration.

Concerning information exchange, CSR representatives in subsidiaries should participate in internal international meetings and use formal and informal mechanisms (intranet, internal reports, etc.) to transmit local information to headquarters and other subsidiaries. Representatives in different areas should participate in CSR meetings to exchange specific information about their areas with other areas.

Concerning awareness activities, CSR representatives in subsidiaries should constantly be aware of environmental and social concerns (on the part of headquarters and other subsidiaries). Headquarters managers should also constantly be aware of the concerns of subsidiaries. These constant interactions can disseminate the CSR values continuously through headquarters and subsidiaries.

Finally, concerning definition of objectives, CSR representatives in subsidiaries should adapt macro objectives into local realities and inform Headquarters about these adaptations. This can influence 
headquarters' definition of CSR objectives, helping with the macro strategy. Consequently, headquarters managers should be flexible when listening to and assisting the Subsidiaries in the implementation of these adapted actions. In addition, headquarters managers should also integrate the areas representatives' demands to recognize specific characteristics that can form CSR objectives.

\section{Limitations and Future Research}

We highlight some limitations of this study. It is an exploratory study and only begins to shed light on the link between CSR and headquarters/subsidiary integration. In terms of data collection, the research has limitations related to the number of interviews with the same managers. Considering the managers' agendas, we could conduct only one interview with each individual. We also limited the data collection to employees from the CSR area and from the corporate level. With regard to the data analysis, it was not possible to use all of the analyzed documents in the presented analysis. Many of these documents can be found on the MNCs' websites.

As a topic little addressed by the MNC and CSR literature, a future research agenda for the influence of transverse CSR structure on headquarters/subsidiary integration can be established. We suggest that the three propositions presented here could be more thoroughly explored and tested. A more extensive analysis relating countries' cultural and institutional aspects can be pursued. Questions such as the following can be the basis of future research: What are the impacts of different types of formal and informal information exchange mechanisms on headquarters/subsidiary integration? What are the impacts of different types of formal and informal awareness process (concerning sustainable development) mechanisms on headquarters/subsidiary integration? What are the impacts of different types of formal and informal objective definition processes on headquarters/subsidiary integration? How do information exchange, awareness activities and definition of objectives influence each other and increase or decrease headquarters/subsidiary integration?

Finally, we highlight the importance of studying this link between transverse CSR structure and headquarters/subsidiary integration, considering the increasing worldwide demand for sustainable development projects and their potential impacts.

\section{REFERENCES}

Aguilera, R. V., Rupp, D. E., Williams, C. A., \& Ganapathi, J. (2007). Putting the S back in corporate social responsibility: a multilevel theory of social change in organizations. Academy of Management Review, 32(3), 836-863.

Allaire, Y. (1984). Theories of organizational culture. Organization Studies, 5(3), 193-227.

Baliga, B. R., \& Jaeger, A. M. (1984). Multinational corporations: control systems and delegation issues. Journal of International Business Studies, 15(2), 25-40.

Bansal, P. (2003). From issues to actions: the importance of individual concerns and organizational values in responding to natural environmental issues. Organization Science, 14(5), 510-527.

Bansal, P. (2005). Evolving sustainably: a longitudinal study of corporate sustainable development. Strategic Management Journal, 26(3), 197-218.

Bansal, P., \& Roth, K. (2000). Why companies go green: a model of ecological responsiveness. Academy of Management Journal, 43(4), 717-736.

Barin-Cruz, L., Pedrozo, E. A., Bacima, R., \& Queiroz, B. (2007). Company and society: the "caras do Brasil” (Faces of Brazil) program as leverage for sustainable development. Management Decision, 45(8), 1297-1319. 
Barnett, M. L. (2007). Stakeholder influence capacity and the variability of financial returns to corporate social responsibility. Academy of Management Review, 33(3), 794-816.

Basu, K., \& Palazzo, G. (2008). Corporate social responsibility: a process model of sensemaking. Academy of Management Review, 33(1), 122-136.

Dam, L., \& Scholtens, B. (2008). Environmental regulation and MNEs location: does CSR matter? Ecological Economics, 67(1), 55-65.

Edstrom, A., \& Galbraith, J. (1977). Transfer of managers as a coordination and control strategy in multinational organizations. Administrative Science Quarterly, 22(2), 248-263.

Eisenhardt, K. M. (1989). Building theory from case studies research. Academy of Management Review, 14(4), 532-550.

Elis, K. M. (2000). Strategic context, knowledge flows, and the competitiveness of MNCs: a procedural justice approach. Competitiviness Review, 10(1), 9-24.

European Commission. (2002). Communication from the commission concerning corporate social responsibility: a business contribution to sustainable development. Retrieved March 8, 2008, from http://europa.eu.int/comm/employment_social/soc-dial/csr/csr2002_en.pdf

Fergus, A. H. T., \& Rowney, J. I. A. (2005). Sustainable development: epistemological frameworks \& an ethic of choice. Journal of Business Ethics, 57(2), 197-207.

Harzing, A. W. (2001). An analysis of the functions of international transfer of managers in MNCs. Employee Relations, 23(6), 581-598.

Husted, B. W. (2003). Governance choices for corporate social responsibility: to contribute, collaborate or internalize? Long Range Planning, 36(5), 481-498.

Jaeger, A. M. (1983). The transfer of organizational culture overseas: an approach to control in the multinational corporation. Journal of International Business Studies, 14(2), 91-114.

Kim, W. C., \& Mauborgne, R. (1993). Procedural justice, attitudes, and subsidiary top management compliance with multinationals' corporate strategic decisions. Academy of Management Journal, 36(3), 502-526.

Kim, W. C., \& Mauborgne, R. A. (1991). Implementing global strategies: the role of procedural justice. Strategic Management Journal, 12(S1), 125-143.

Kranias, D. S. (2000). Cultural control: the case of Japanese multinational companies and their subsidiaries in the UK. Management Decision, 38(9), 638-648.

Kranias, D. S. (2001). Formal control of the Japanese multinational companies to their subsidiaries in the UK. Managerial Auditing Journal, 15(5), 297-306.

Levis, J. (2006). Adoption of corporate social responsibility codes by multinational companies. Journal of Asian Economics, 17(1), 50-55.

Mackey, A., Mackey, T. B., \& Barney, J. B. (2007). Corporate social responsibility and firm performance: investor preference and corporate strategies. Academy of Management Review, 32(3), 817-835.

Martinez, J. I., \& Jarillo, J. C. (1989). The evolution of research on coordination mechanisms in multinational corporations. Journal of International Business Studies, 20(3), 489-514.

Matten, D., \& Moon, J. (2008). "Implicit” and "explicit” CSR: a conceptual framework for a comparative understanding of corporate social responsibility. Academy of Management Review, 33(2), 404-424. 
Molm, L. D., Takahashi, N., \& Peterson, G. (2003). In the eye of the beholder: Procedural Justice in Social Exchange. American Sociological Review, 68(1), 128-152.

Nohria, N., \& Ghoshal, S. (1994). Differentiated fit and shared values: alternatives for managing headquarters-Subsidiary relations. Strategic Management Journal, 15(6), 491-502.

Ouchi, W. G., \& Jaeger, A. M. (1978). Type Z organization: stability in the midst of mobility. Academy of Management Review, 3(2), 305-314.

Payne, D. M., \& Raiborn, C. A. (2001). Sustainable development: the ethics support the economics. Journal of Business Ethics, 32(2), 157-168.

Perlmuter, H. V. (1984). Building the symbolical social enterprise: a social architecture for the future. World Futures, 19(3/4), 271-284.

Raiborn, C. A., \& Payne, D. M. (1990). Corporate codes of conduct: a collective conscience and continuum. Journal of Business Ethics, 9(11), 879-889.

Ramus, C. A., \& Steger, U. (2000). The roles of supervisory support behaviors and environmental policy in employee "ecoinitiatives" at leading-edge European companies. Academy of Management Journal, 43(4), 605-626.

Sharma, S. (2000). Managerial interpretations and organizational context as precidtors of corporate choise of environmental strategy. Academy of Management Journal, 43(4), 681-697.

Siggelkow, N. (2007). Persuasion with case studies. Academy of Management Journal, 50(1), 20-24.

Steurer, R., Langer, M. E., Konrad, A., \& Martinuzzi, A. (2005). Corporations, stakeholders and sustainable development I: a theoretical exploration of business-society relations. Journal of Business Ethics, 61(3), 263-281.

Taggart, J. H. (1997). Autonomy and procedural justice: a framework for evaluating subsidiary strategy. Journal of Internacional Business Studies, 28(1), 51-76.

World Commission on Environmental and Development. (1987). Our common future. New York, NY: Oxford University Press. 